\title{
Naturally Occurring Broad-Spectrum Powdery Mildew Resistance in a Central American Tomato Accession Is Caused by Loss of Mlo Function
}

\author{
Yuling Bai, ${ }^{1}$ Stefano Pavan,, ${ }^{1,2}$ Zheng Zheng, ${ }^{1}$ Nana F. Zappel, ${ }^{3}$ Anja Reinstädler, ${ }^{3}$ Concetta Lotti, ${ }^{2}$ \\ Claudio De Giovanni, ${ }^{2}$ Luigi Ricciardi, ${ }^{2}$ Pim Lindhout, ${ }^{1}$ Richard Visser, ${ }^{1}$ Klaus Theres, ${ }^{4}$ and \\ Ralph Panstruga ${ }^{3}$
}

\begin{abstract}
${ }^{1}$ Laboratory of Plant Breeding, Plant Sciences Group, Wageningen University, Droevendaalsesteeg 1, 6708 PB Wageningen, The Netherlands; ${ }^{2}$ Department of Agroforestry, Enviromental Biology and Chemistry, Section of Genetics and Plant Breeding, University of Bari, Via Amendola 165/A, 70126 Bari, Italy; ${ }^{3}$ Max-Planck Institute for Plant Breeding Research, Department of Plant-Microbe Interactions, Carl-von-Linné-Weg 10, D-50829 Köln, Germany; ${ }^{4}$ Max-Planck Institute for Plant Breeding Research, Department of Plant Breeding and Genetics, Carl-von-Linné-Weg 10, D-50829 Köln, Germany
\end{abstract}

Submitted 15 June 2007. Accepted 18 September 2007.

\begin{abstract}
The resistant cherry tomato (Solanum lycopersicum var. cerasiforme) line LC-95, derived from an accession collected in Ecuador, harbors a natural allele (ol-2) that confers broad-spectrum and recessively inherited resistance to powdery mildew (Oidium neolycopersici). As both the genetic and phytopathological characteristics of ol-2-mediated resistance are reminiscent of powdery mildew immunity conferred by loss-of-function mlo alleles in barley and Arabidopsis, we initiated a candidate-gene approach to clone $\mathrm{Ol}$ 2. A tomato Mlo gene (SlMlo1) with high sequence-relatedness to barley Mlo and Arabidopsis AtMLO2 mapped to the chromosomal region harboring the $\mathrm{Ol-2}$ locus. Complementation experiments using transgenic tomato lines as well as virus-induced gene silencing assays suggested that loss of SlMlo1 function is responsible for powdery mildew resistance conferred by $o l-2$. In progeny of a cross between a resistant line bearing $o l-2$ and the susceptible tomato cultivar Moneymaker, a 19-bp deletion disrupting the SlMlo1 coding region cosegregated with resistance. This polymorphism results in a frameshift and, thus, a truncated nonfunctional SIMlo1 protein. Our findings reveal the second example of a natural mlo mutant that possibly arose postdomestication, suggesting that natural mlo alleles might be evolutionarily short-lived due to fitness costs related to loss of mlo function.
\end{abstract}

Additional keywords: comparative genetics, co-orthologs, introgression lines, pleiotropic effects.

Powdery mildew is a common disease of higher plant species that is caused by obligate biotrophic Ascomycete fungi belonging to the order Erysiphales. Worldwide, approximately 500 powdery mildew species are able to colonize about 10,000 distinct plant species (Takamatsu 2004). The disease is particularly

\section{S. Pavan and Z. Zheng contributed equally to this work.}

Corresponding authors: R. Panstruga; E-mail panstrug@mpiz-koeln.mpg.de; Telephone: +49-221-5062-316; Fax: +49-221-5062-353, and Y. Bai: E-mail: bai.yuling@wur.nl; Telephone: +31-317-477284; Fax: +31-317-483457.

*The $e$-Xtra logo stands for "electronic extra" and indicates that two supplemental figures are published online. prevalent in temperate and humid climates, where it frequently causes significant yield losses in agricultural settings, including greenhouse and field tomato (Solanum lycopersicum) farming. Powdery mildew caused by Oidium neolycopersici has recently been recognized as a worldwide emerging pathogen on tomato (Jones et al. 2001). There are two known tomato powdery mildew species in the Oidium genus, O. lycopersici occurring in Australia and $O$. neolycopersici in the rest of the world (Kiss et al. 2001). Several powdery mildew (Oidium neolycopersici, $\mathrm{Ol}$ ) resistance genes have been described and mapped in tomato, of which most confer dominantly inherited, isolate-specific resistance (Bai et al. 2005). However, ol-2 mediates recessively inherited broad-spectrum (non-isolate-specific) resistance to O. neolycopersici (Bai et al. 2005; Ciccarese et al. 1998). The ol-2 allele originates from a wild accession of $S$. lycopersicum var. cerasiforme (cherry tomato), a close relative of common cultivated tomato that is thought to represent an admixture of wild and cultivated tomatoes (Ciccarese et al. 1998; Nesbitt and Tanksley 2002). The respective accession, LA1230, was originally collected in 1970 in Ecuador (University of California Davis, Tomato Genetics Resource Center database) in a home garden and park area. Based on genetic mapping, ol-2 was found to reside around the centromere of tomato chromosome 4 (De Giovanni et al. 2004). Histological analysis of the host-pathogen interaction of an ol-2-containing line revealed an early abortion of fungal pathogenesis associated with the formation of plant cell-wall appositions (papillae) at the attempted fungal entry sites (Bai et al. 2005). Taken together, these characteristics (recessive inheritance, broadspectrum resistance profile, early termination of fungal pathogenesis) are reminiscent of powdery mildew resistance in barley (Hordeum vulgare) and thale cress (Arabidopsis thaliana) conferred by loss-of-function mlo (mildew resistance locus o) alleles (Consonni et al. 2006; Jørgensen 1992).

In land plants, Mlo genes comprise small to medium-sized families encoding a novel type of plant-specific integral membrane proteins with one or more as-yet-unknown biochemical functions (Devoto et al. 1999, 2003). In the monocot barley and the dicot Arabidopsis, mutations in particular Mlo genes result in broad-spectrum powdery mildew resistance (Büschges et al. 1997; Consonni et al. 2006). It is thought that the respective protein isoforms modulate vesicle-associated defense responses at the cell periphery and that the powdery mildew 
pathogen possibly exploits these proteins for successful hostcell entry (Panstruga 2005a). While, in barley, loss-of-function of a single Mlo gene suffices to confer full resistance, unequal genetic redundancy (Briggs et al. 2006) between three phylogenetically closely related Mlo co-orthologs (AtMLO2, AtMLO6 and AtMLO12; Panstruga 2005b) results in a more complex scenario in Arabidopsis; absence of AtMLO2 confers partial powdery mildew resistance that becomes enhanced in Atmlo2 Atmlo6 or Atmlo2 Atmlo12 double mutants. Full resistance requires loss-of-function of all three co-orthologs, i.e., an Atmlo2 Atmlo6 Atmlo12 triple mutant (Consonni et al. 2006). Barley mlo mutants have been known for more than 60 years (Freisleben and Lein 1942) and have been successfully employed in European barley agriculture for more than 25 years (Lyngkjaer et al. 2000), emphasizing the principal durability of mlo-mediated disease resistance under agricultural conditions.

In case of barley, in addition to a broad range of induced mutations (Büschges et al. 1997; Panstruga et al. 2005; Piffanelli et al. 2002), one natural allele (mlo-11) has been described (Piffanelli et al. 2004). This allele derives from a barley landrace, an intermediate between wild and cultivated barley, initially found in Ethiopia. At the molecular level, it is characterized by the presence of a complex tandem repeat array, comprising Mlo 5' regulatory and partial coding sequences, that localize upstream of a fully intact Mlo wild-type copy (Piffanelli et al. 2004). Experimental evidence points to a transcriptional 'read-through' phenomenon caused by the presence of the upstream repeat units, interfering with proper transcription of the downstream Mlo wild-type copy (Piffanelli et al. 2004). Interestingly, the mlo-11 allele is meiotically unstable, resulting in rare meiotic reversion events that give rise to susceptible progeny. Reversion to susceptibility was found to coincide with a loss of the repeat array and restoration of wild-type-like Mlo transcript and Mlo protein levels (Piffanelli et al. 2004).

Here, we used a targeted approach based on comparative genetics to clone the tomato $\mathrm{Ol}-2$ gene. We selected and mapped two SlMlo candidate genes. The chromosomal location as well as genetic gain- and loss-of-function experiments suggested that SlMlol is $\mathrm{Ol-2}$. Sequence analysis revealed a short deletion in the $\mathrm{Ol}-2$ coding region of the resistant tomato accession that cosegregated with resistance.

\section{RESULTS}

We first assessed whether the tomato powdery mildew pathogen, $O$. neolycopersici, is principally amenable to mlo-mediated resistance. Besides tobacco and other host plants, O. neolycopersici has been reported to be virulent on A. thaliana (Xiao

Table 1. Infection phenotypes of Arabidopsis mlo mutants upon challenge with Oidium neolycopersici

\begin{tabular}{llcl}
\hline & \multicolumn{3}{c}{ Disease index (DI) $^{\mathbf{a}}$} \\
\cline { 2 - 4 } Genotype & $\mathbf{8} \mathbf{d p i}^{\mathbf{b}}$ & $\mathbf{1 3} \mathbf{~ d p i}$ & $\mathbf{1 5} \mathbf{~ d p i}$ \\
\hline Col-0 & $1.6 \pm 0.5^{\mathbf{c}}$ & $2.8 \pm 0.4$ & $2.8 \pm 0.4$ \\
Atmlo2 & 0.0 & $1.0 \pm 0.0$ & $1.0 \pm 0.0$ \\
Atmlo6 & 0.0 & $2.0 \pm 0.0$ & $1.5 \pm 0.0$ \\
Atmlo12 & 0.0 & $2.0 \pm 0.0$ & $2.0 \pm 0.0$ \\
Atmlo2 Atmlo6 & 0.0 & 0.0 & 0.0 \\
Atmlo2 Atmlo12 & 0.0 & 0.0 & 0.0 \\
Atmlo6 Atmlo12 & 0.0 & $2.0 \pm 0.0$ & $1.5 \pm 0.5$ \\
Atmlo2 Atmlo6 Atmlo12 & 0.0 & 0.0 & 0.0 \\
\hline
\end{tabular}

${ }^{\text {a }}$ To semiquantitatively assess infection phenotypes, the following DI scale was used: $0=$ no visible fungal sporulation, $1=$ few fungal colonies, $2=$ up to $30 \%$ of the leaf area covered with fungal colonies, and $3=$ more than $30 \%$ of the leaf area covered with fungal colonies.

${ }^{\mathrm{b}} \mathrm{dpi}=$ days postinoculation.

${ }^{c}$ DI mean \pm standard deviation of five plants per genotype are presented. et al. 2001). We thus inoculated susceptible Col-0 wild-type plants and the previously described set of resistant Arabidopsis mlo mutants with $O$. neolycopersici. In Arabidopsis, three phylogenetically closely related Mlo co-orthologs, AtMLO2, AtMLO6, and AtMLO12, (Panstruga 2005b), exhibit unequal genetic redundancy with respect to powdery mildew infection phenotypes. Atmlo2 mutants are partially resistant to adapted powdery mildews, while Atmlo2 Atmlo6 and Atmlo2 Atmlo12 double mutants exhibit increased, and the Atmlo2 Atmlo6 Atmlo12 triple mutant full resistance (Consonni et al. 2006). Reminiscent of this scenario, Atmlo2 plants were partially resistant and its derived double (Atmlo2 Atmlo6, Atmlo2 Atmlo12) and triple (Atmlo2 Atmlo6 Atmlo12) mutants showed full resistance to $O$. neolycopersici (Fig. 1; Table 1). We conclude that $O$. neolycopersici, similar to powdery mildews colonizing barley (Blumeria graminis f. sp. hordei) or Arabidopsis (e.g., Golovinomyces cichoracearum and Golovinomyces orontii), is sensitive to mlo-based resistance.

Given the fact that $O$. neolycopersici requires host Mlo function for pathogenesis and based on the genetic and phytopathological similarities between ol-2-mediated powdery mildew resistance and the well-characterized loss-of-function mlo mutants in barley and Arabidopsis, we initiated a candidate approach to clone $\mathrm{Ol}-2$. We inspected the publicly available tomato expressed sequence tag (EST) collections by BLAST analysis for cDNAs with a significant sequence relatedness to AtMLO2-encoded transcripts. We identified two EST contigs comprising 12 and three EST sequences, respectively, that correspond to cDNAs of two distinct genes, which we designated SlMlo1 and SlMlo2 (Fig. 2A). While multiple overlapping EST sequences enabled the inference of a conceptual full-length SlMlo1 cDNA sequence (National Center for Biotechnology Information [NCBI] UniGene database, tomato Les.746), SlMlo2 was only represented as a partial cDNA covering the $3^{\prime}$ end of the coding sequence (Fig. 2). Tissue origin of the respective EST indicates that SlMlol is ubiquitously expressed

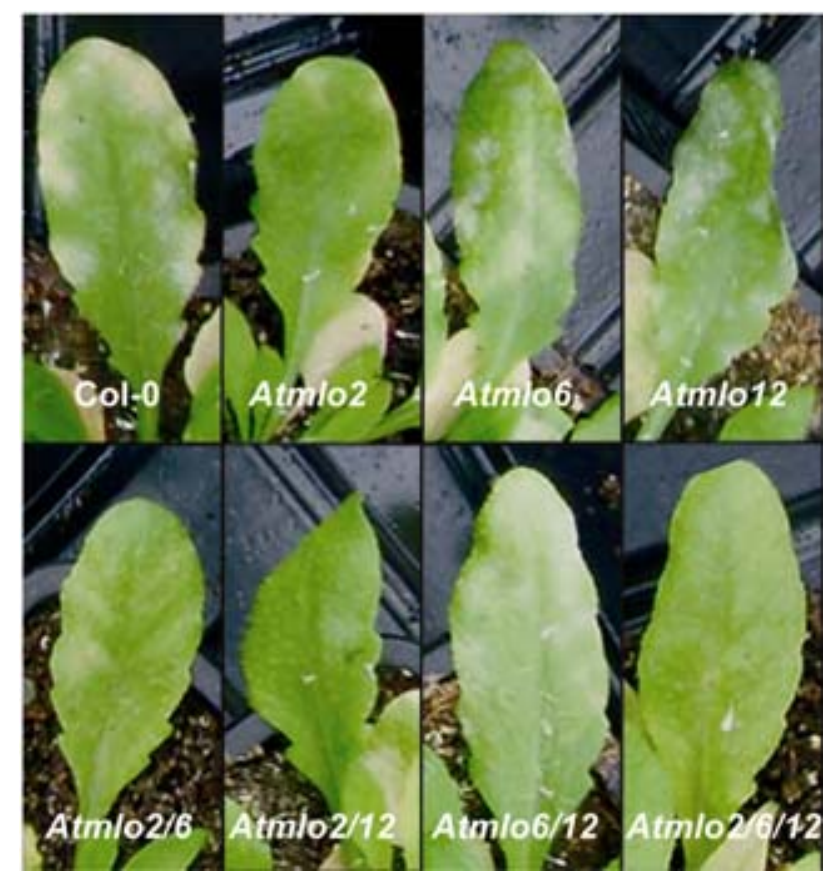

Fig. 1. Oidium neolycopersici requires AtMLO2 function for pathogenesis on Arabidopsis thaliana. Exemplary infection phenotypes of rosette leaves of 7-week-old $A$. thaliana wild-type (Col-0) plants and T-DNA insertion mutants (Atmlo2, Atmlo6, Atmlo12 single, double, and triple mutants) inoculated with $O$. neolycopersici. The photograph was taken 15 days postinoculation. The experiment was repeated once with similar results. 
(leaf, callus, flower), while expression of SlMlo2 appears to be predominant in tomato breaker fruits (data not shown). We designed oligonucleotide primers flanking the deduced sequence contigs and performed reverse transcription polymerase chain reaction (RT-PCR) on RNA obtained from wild-type tomato leaves to verify the predicted SlMlo1 and SlMlo2 cDNA sequences. This confirmed the expression of either gene in tomato leaves and validated the nucleotide sequences of the respective EST-derived cDNA contigs (data not shown). Phylogenetic analysis comprising all Arabidopsis MLO protein sequences as well as SIMlo1 and SIMlo2 revealed that the two deduced tomato proteins cluster in the same clade as AtMLO2, AtMLO6, and AtMLO12 (Fig. 3). Based on this finding and the presence of a shared distinctive polypeptide motif at the $\mathrm{C}$ terminus of the encoded polypeptides (Fig. 2B), which is considered to be diagnostic of an orthologous phylogenetic relationship (Panstruga 2005b), SlMlo1 and SlMlo2 likely represent co-orthologs of AtMLO2, AtMLO6, and AtMLO12.

A collection of $S$. lycopersicum $\times S$. pennellii introgression lines (IL; Eshed and Zamir 1995) provides an efficient tool for the rapid mapping of genes to tomato chromosomal segments. Using a core set of 50 IL covering each of the 12 tomato chro-

A

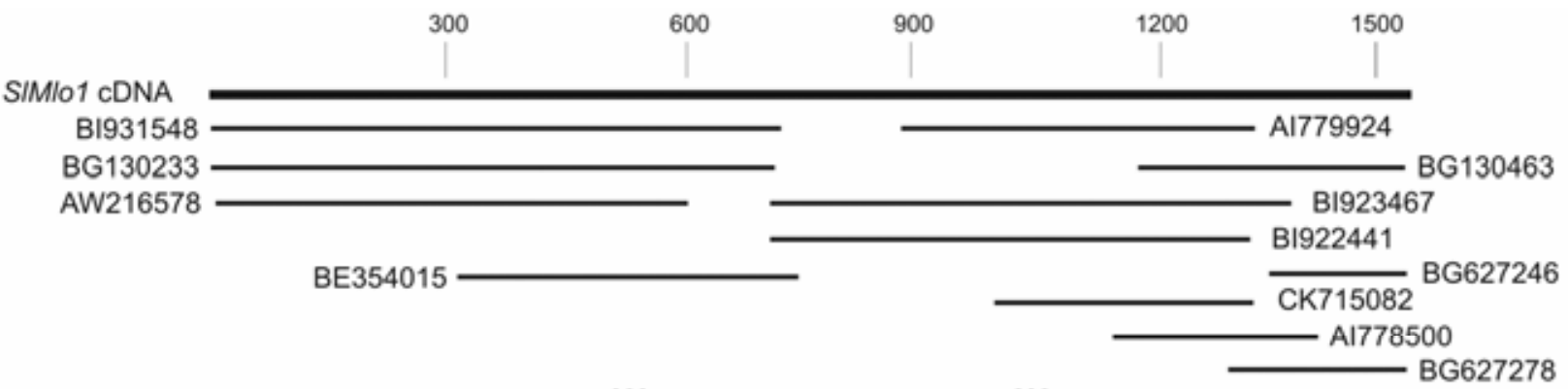

300

600

SIMlo2 cDNA (partial)

BG127794

BM409501

BF112469

B

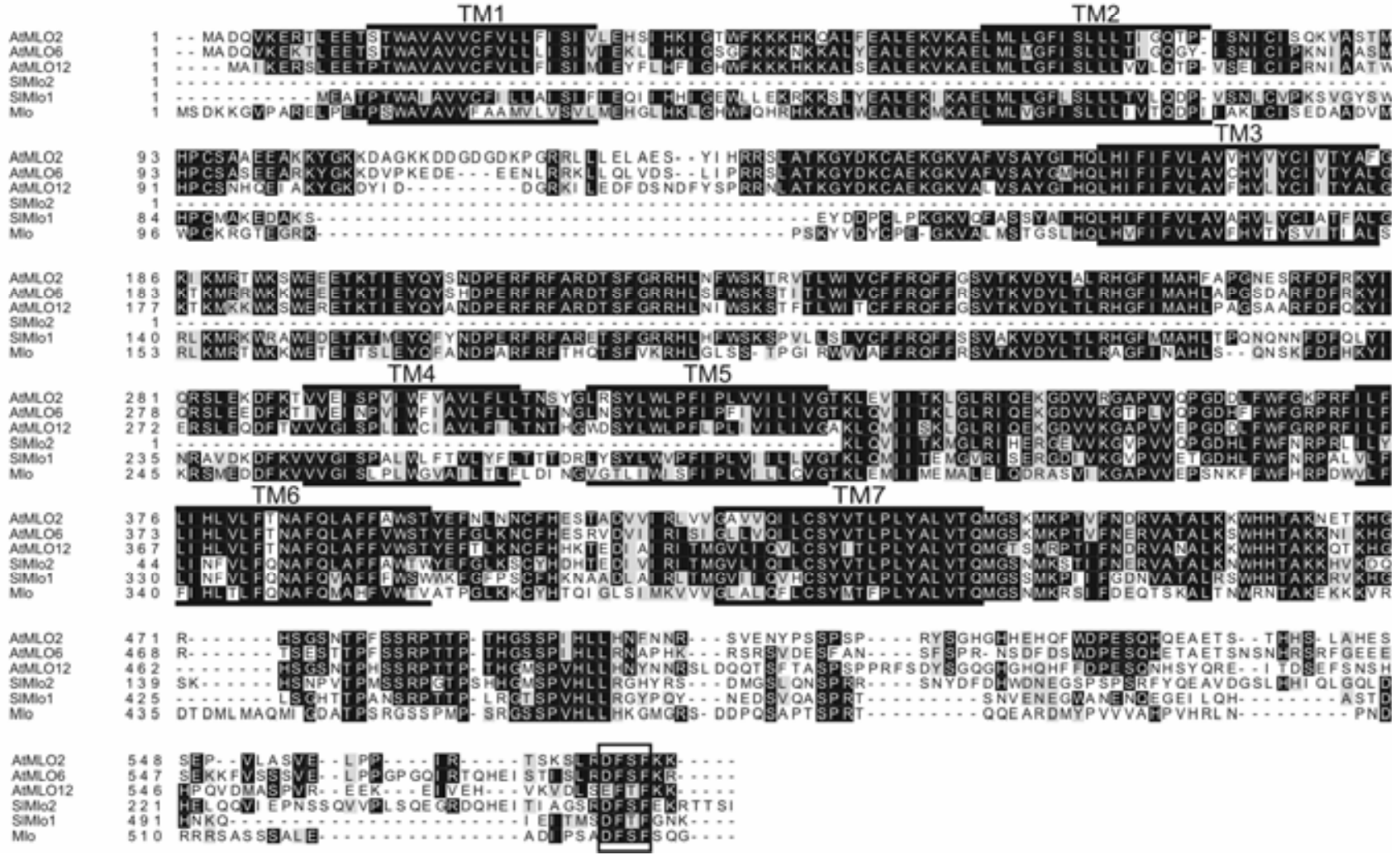

Fig. 2. SlMlo1 and SlMlo2 encode polypeptides that are highly sequence related to barley Mlo, Arabidopsis AtMLO2, AtMLO6, and AtMLO12. A, The scheme represents the coverage of SIMlo1 (top bold line) and SIMlo2 (bottom bold line) cDNAs by expressed sequence tag (EST) sequences (thin lines) as revealed by BLASTN analysis using the SIMlo1 or SlMlo2 cDNA contig as query sequences, respectively. Designations next to the EST-signifying lines specify GenBank accession numbers. Scales above cDNAs indicate length in nucleotides. Note the different scales for SlMlo1 and SlMlo2. B, Multiple amino-acid sequence alignment of barley Mlo, tomato SIMlo1 and SIMlo2 as well as Arabidopsis AtMLO2, AtMLO6, and AtMLO12 polypeptide sequences. The alignment was generated by CLUSTALW using the default parameter. Positions of the seven transmembrane regions (TM1 through TM7) inferred from the experimentally determined topology of barley Mlo (Devoto et al. 1999) are indicated by bars above and below the sequences. The C-terminal D/E-F-S/T-F tetra-peptide sequence, one of several motifs characteristic of barley Mlo orthologs (Panstruga 2005b), is boxed. 
mosomes with overlapping introgressed segments of $S$. pennellii, we determined a likely localization of SlMlol at the center of chromosome 4 in a small region that also harbors the ol-2containing interval (De Giovanni et al. 2004), while SlMlo2 was found to reside on top of chromosome 6 (Fig. 4). Since ol2 was previously unequivocally found to be a single recessive locus located on tomato chromosome 4 (De Giovanni et al. 2004), we focused in the following on SlMlol as a candidate for $\mathrm{Ol}-2$ and excluded SIMlo2 from further analysis.

We performed semiquantitative RT-PCR analyses in a longterm timecourse experiment following powdery mildew challenge, to study SIMlol expression in susceptible $\mathrm{Ol}-2$ wildtype and resistant ol-2 (line R28) mutant plants. We observed moderately reduced SlMlo1 transcript accumulation in line R28 as compared with wild-type plants at all tested time points (Fig. 5A). Similar results were obtained upon comparison of SlMlol transcript levels at early timepoints following $O$. neolycopersici inoculation in homozygous susceptible (Ol-2/Ol-2 genotype) and resistant (ol-2/ol-2 genotype) $\mathrm{F}_{2}$ progeny of a cross between the susceptible cv. Moneymaker (MM) and the resistant line R28 (Fig. 5B). Consistent with previous findings in barley (Piffanelli et al. 2002), both $\mathrm{Ol}-2$ and ol-2 genotypes exhibited a noticeable increase in SlMlol transcript levels at early timepoints following powdery mildew challenge (Fig. 5B).

To directly assess a potential role of SlMlol in conferring powdery mildew susceptibility in wild-type tomato, we initiated both genetic gain- and loss-of-function experiments. We reasoned that, if loss of SlMlol function was responsible for resistance conferred by the $o l-2$ gene, then strong constitutive expression of a SlMlol transgene should restore susceptibility in resistant plants bearing the ol-2 allele. Vice versa, SlMlol gene silencing in susceptible tomato wild-type plants should result in enhanced powdery mildew resistance. For this and the following experiments, we used a resistant $F_{3}$ line, R26, of a cross between the susceptible cv. Super Marmande (SM) and the original resistant line $S$. lycopersicum var. cerasiforme LC95 (De Giovanni 2004). We generated a binary vector harboring SlMlol under control of the strong constitutive Cauliflower mosaic virus $35 \mathrm{~S}$ promoter and transformed tomato line R26 with the respective construct. Upon selection on kanamycin, we obtained 11 independent transgenic lines. We performed semiquantitative as well as real-time RT-PCR, using RNA extracted from leaf material of $\mathrm{T}_{1}$ plants to assess expression levels of the SlMlol transgene. Both types of analysis revealed that transgenic lines 3,10, and 11 expressed the highest levels of wild-type SlMlol cDNA (Fig. 6A and B). We challenged selfed progeny $\left(\mathrm{T}_{2}\right.$ plants) of the individual transgenic lines with $O$. neolycopersici and observed restoration of macroscopically visible powdery mildew growth among the offspring of the two lines (lines 10 and 11) that, beforehand, exhibited strongest transgene expression in the $\mathrm{T}_{1}$ generation (Fig. 6C and $\mathrm{D} ; \mathrm{T}_{1}$ seeds of transgenic lines $1,3,6$, and 7 did not germinate, preventing analysis of the respective $T_{2}$ progeny). Powdery mildew infection phenotypes of susceptible segregants derived from transgenic lines 10 and 11 were comparable to the fully susceptible cv. MM (disease index [DI] score = $3)$. PCR fingerprint analysis employing codominant markers TOM316 and U3-2HhaI, closely linked to ol-2 (Pavan et al. in press), confirmed the identity of the parental line (R26) used for transformation and excluded the possibility of a seed contamination (data not shown). In total, $28 \mathrm{~T}_{2}$ plants (12 from line 10 and 16 from line 11) were tested, and susceptibility to $O$. neolycopersici segregated in both these $\mathrm{T}_{2}$ generations in an approximately 3:1 (susceptible/resistant) ratio, suggesting the presence of single-transgene loci in both of the transgenic lines (Table 2). Occurrence of susceptible $\mathrm{T}_{2}$ plants and segregation in the $\mathrm{T}_{2}$ progeny indicates that restored susceptibility is a heritable genetic trait upon transgenic expression of SlMlol.

For genetic loss-of-function experiments, we engineered a transgenic Tobacco rattle virus (TRV) harboring a SlMlo1 fragment for virus-induced gene silencing (VIGS) experiments. Upon inoculation of the modified virus (TRV-SlMlol) on susceptible wild-type tomato plants of S. lycopersicum cv. $\mathrm{MM}$ and subsequent challenge with $O$. neolycopersici, we observed a dramatic reduction of macroscopically visible powdery mildew colonies as compared with inoculation with wildtype TRV (Fig. 7). Two independent VIGS assays yielded

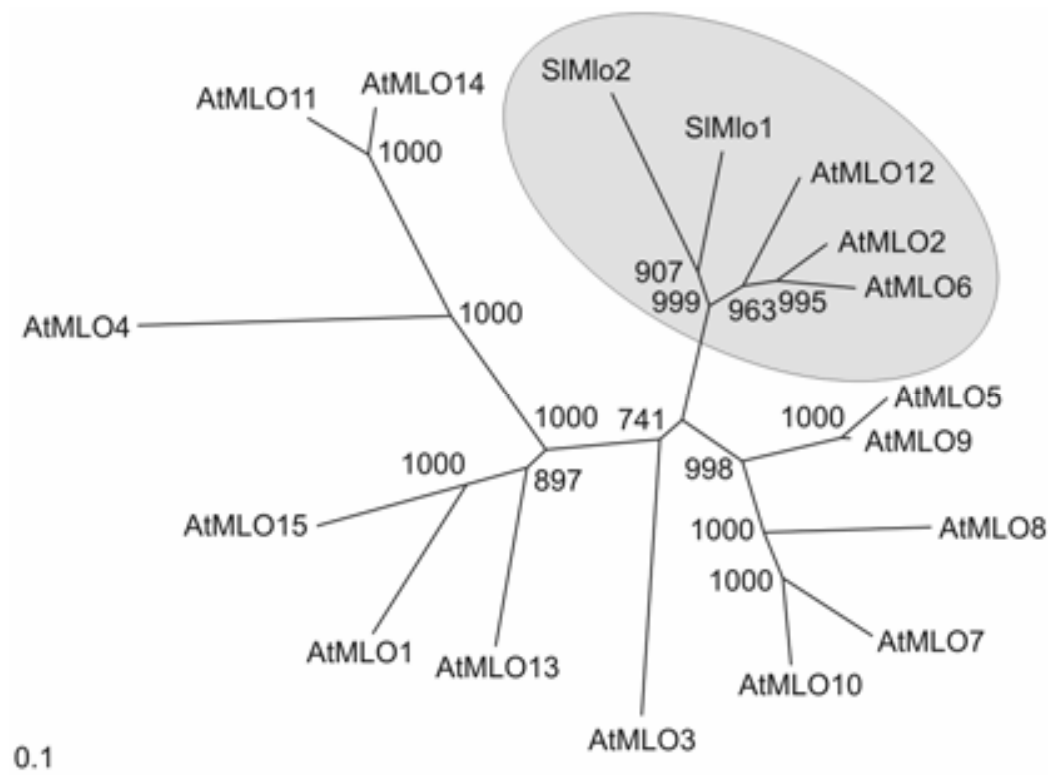

Fig. 3. A neighbor-joining phylogenetic tree of Arabidopsis and selected tomato MLO proteins. SIMlo1 and SIMlo2 are co-orthologs of AtMLO2, AtMLO6, and AtMLO12. The unrooted radial tree comprises all 15 Arabidopsis MLO paralogs (AtMLO1 to AtMLO15; Devoto et al. 2003) as well as SIMlo1 and SIMlo2 and was established on the basis of an optimized multiple-sequence aligment using the PHYLIP software package. Numbers above nodes indicate bootstrap values (based on 1,000 replicates) that support the respective branch. The scale (left bottom corner) indicates the number of amino-acid exchanges per site. The circled clade shaded in light gray harbors potential tomato (SIMlo1 and SIMlo2) and Arabidopsis (AtMLO2, AtMLO6, and AtMLO12) co-orthologs. 
comparable results. Taken together with the complementation experiments described above, this finding suggests that, indeed, a loss of SlMlol function is responsible for powdery mildew resistance conferred by the recessively inherited ol-2 gene.
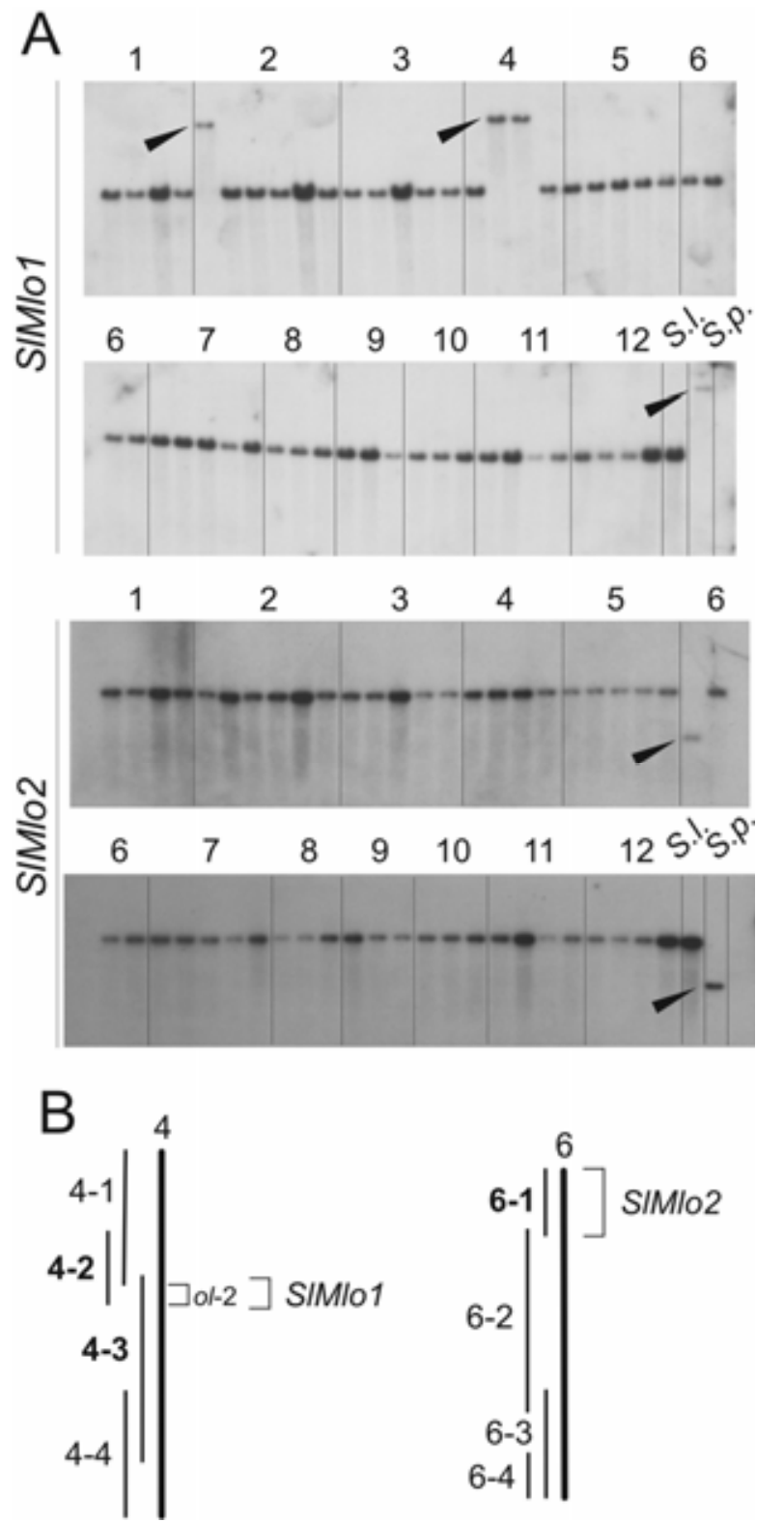

Fig. 4. Introgression line (IL)-based mapping of SlMlo1 and SlMlo2. A, Gel blot hybridization of labeled SlMlo1 (top panels) or SIMlo2 (bottom panels) cDNA fragments on filters comprising restriction-digested genomic DNAs of a core set of Solanum lycopersicum $\times$ Solanum pennellii IL and respective parental lines. Genomic DNAs were either digested with restriction enzyme BglII (SlMlo1) or EcoRV (SlMlo2). Parental polymorphisms in S. pennellii and IL showing the particular polymorphism are highlighted by black arrowheads. Numbers above gel sections indicate the lines representing the respective tomato chromosome. S.l. = Solanum lycopersicum; S.p. $=$ Solanum pennellii (parental lines). Note the additional SlMlo1 polymorphism in line 2-1 (upper panel). Occurrence of two overlapping chromosomal segments of chromosome 4 (lines 4-2 and 4-3) and the absence of a second hybridizing band in any lane of this blot suggests that this polymorphism is most likely due to the presence of an ectopic genomic fragment of chromosome 4 in line 2-1 (an impurity of the IL; Bonnema et al. 2002). B, Scheme depicting the interpretation of the IL-based mapping shown in A. Solid thick lines represent tomato chromosome 4 (left) and 6 (right). Thin lines designate chromosomal segments covered by the respective IL, bold numbers highlight segments harboring a sequence polymorphism in SlMlo1 or SlMlo2. The previously determined map position of ol-2 (De Giovanni et al. 2004) as well as the deduced intervals harboring SIMlo1 and SIMlo2 are indicated.
In principle, lack of the SlMlol transcript or alterations in the encoded cDNA or polypeptide sequence could lead to the observed disease-resistance phenotype. In barley, all induced mutants analyzed to date were found to confer changes in the Mlo coding sequence (Büschges et al. 1997; Panstruga et al. 2005; Piffanelli et al. 2002), while the sole known natural mlo allele, $m l o-11$, is characterized by severely perturbed Mlo transcript levels (Piffanelli et al. 2004). Since RT-PCR analysis revealed SlMlol transcript accumulation in both $\mathrm{Ol}-2$ and $\mathrm{ol}-2$ genotypes (discussed above), we analyzed SlMlol cDNA sequences of tomato wild-type plants (cv. SM) and the resistant progeny $\left(\mathrm{F}_{3}\right.$ line $\left.\mathrm{R} 26\right)$ of $S$. lycopersicum var. cerasiforme LA1230. While the cDNA sequence of SM was identical to the wild-type SlMlol reference sequence (GenBank accession number AY967408; NCBI UniGene tomato Les.746), we found

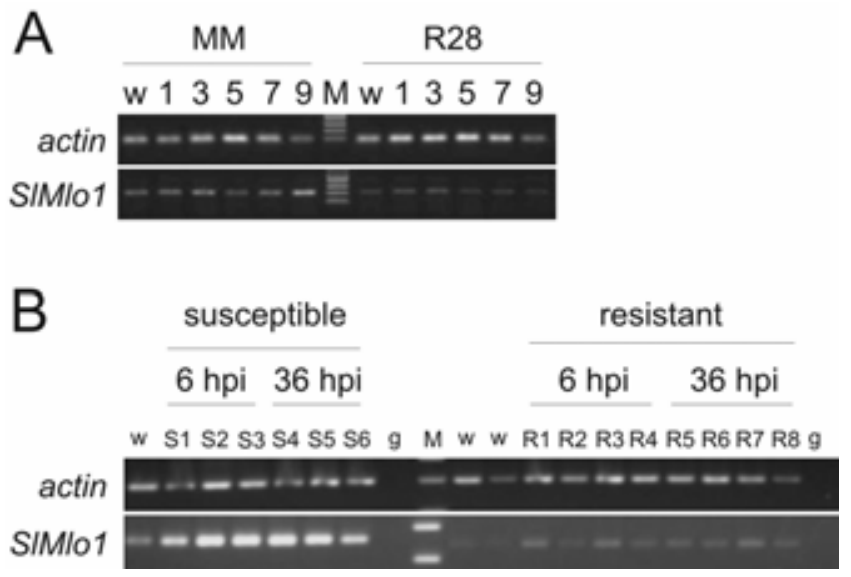

Fig. 5. SlMlo1 transcript accumulation upon powdery mildew challenge. A, Semiquantitative reverse transcription-polymerase chain reaction (RTPCR) analysis of SIMLO1 and actin transcript levels in susceptible wildtype tomato (cv. Moneymaker $[\mathrm{MM}]$ ) and the powdery mildew resistant $\mathrm{F}_{3}$ line R28. RNAs were extracted from leaves of either unchallenged $(\mathrm{w}=$ water control) or powdery mildew-challenged plants at $1,3,5,7$, and 9 days after inoculation with Oidium neolycopersici. Lane ' $\mathrm{M}$ ' indicates DNA size marker. B, Semiquantitative RT-PCR analysis of SlMlol and actin transcript levels in homozygous susceptible ( $\mathrm{Ol}-2 / \mathrm{Ol}-2$ genotype; lines $\mathrm{S} 1$ to $\mathrm{S} 6$ ) and resistant (ol-2/ol-2 genotype; lines R1 to R8) $\mathrm{F}_{2}$ progeny of a cross between $\mathrm{cv}$. MM and the powdery mildew-resistant $\mathrm{F}_{3}$ line R28. RNAs were extracted from leaves of either unchallenged or powdery mildew-challenged plants at 6 and $36 \mathrm{~h}$ after inoculation with $O$. neolycopersici . Lane $\mathrm{g}=$ amplification using genomic DNA as template, lane $\mathrm{M}=$ DNA size marker. Note the slight size difference (owing to the 19-bp deletion) between SIMLOI cDNAs derived from susceptible (Ol-2) or resistant (ol-2) lines. Absence of products derived from genomic DNA as template likely is due to either the presence of multiple introns in the respective genomic sequences, the potential location of primer binding sites on exon or intron junctions, or both.

Table 2. Segregation analysis of transgenic tomato lines

\begin{tabular}{lccl}
\hline \multicolumn{1}{c}{$\mathbf{T}_{\mathbf{1}}$ generation } & \multicolumn{3}{c}{$\mathbf{T}_{\mathbf{2}}$ generation } \\
\cline { 1 - 3 } \cline { 3 - 4 } Line & Susceptible $^{\mathbf{a}}$ & Resistant $^{\mathbf{a}}$ & $\chi^{\mathbf{2}} \mathbf{( 3 : \mathbf { 1 } \mathbf { b } ^ { \mathbf { b } }}$ \\
\hline 2 & 0 & 22 & n.a. \\
4 & 0 & 16 & n.a. \\
5 & 0 & 16 & n.a. \\
8 & 0 & 12 & n.a. \\
9 & 0 & 11 & n.a. \\
10 & 7 & 5 & $P>0.5$ \\
11 & 12 & 4 & $P>0.9$ \\
\hline
\end{tabular}

${ }^{\text {a }}$ Susceptible plants with a disease index (DI) score of 2 or 3 and resistant plants with a DI of 0 or $1(0=$ no visible fungal sporulation, $1=$ few fungal colonies, $2=$ up to $30 \%$ of the leaf area covered with fungal colonies, and $3=$ more than $30 \%$ of the leaf area covered with fungal colonies).

${ }^{\mathrm{b}}$ n.a. $=$ not applicable. 
a 19-bp deletion in the cDNA of line R26. This sequence alteration leads to a frameshift in the coding region, predicted to result in premature translational termination in the second cytoplasmic loop of SIMlo1 and, thus, a severely truncated protein (Fig. 8). We found the same DNA sequence polymorphism in the genomic sequence of the independent resistant $F_{3}$ line R28 (data not shown). Notably, apart from this difference, the nucleotide sequences of the SlMlol open reading frames of the susceptible SM and the resistant R26 lines were identical (data not shown). We conclude that the resistant natural accession is expected to encode a SlMlol null allele conditioned by a single mutational event in the SlMlol coding region.

We designed oligonucleotide primers flanking the 19-bp deletion in the SIMlol cDNA and analyzed the SIMlol genotype in an $\mathrm{F}_{2}$ population segregating for ol-2-mediated powdery mildew resistance. As judged from PCR data, presence of the 19-bp deletion fully correlated with resistance $(n=106$ ana- lyzed $\mathrm{F}_{2}$ individuals), further substantiating that SlMlol is $\mathrm{Ol}-2$ (Supplementary Fig. 2).

\section{DISCUSSION}

We have shown here that the recessively inherited ol-2-mediated powdery mildew resistance originally identified in a natural accession (LA-1230) of Solanum lycopersicum var. cerasiforme collected in Ecuador is mediated by loss of SlMlol function. The chain of evidence consists of a common map position (Fig. 4B), genetic gain- and loss-of-function experiments (Figs. 6 and 7), as well as cosegregation of a small (19 bp) deletion in the SlMlol coding region with the resistant phenotype (Fig. 8). Taken together, these findings indicate that the resistant mutant derived from the cherry tomato accession LA-1230 encodes a SlMlo1 null allele, caused by a small nucleotide polymorphism in the coding region of the gene.

A 35S::SIMIO1

$\begin{array}{llllllllllllll}1 & 2 & 3 & 4 & 5 & 6 & 7 & 8 & 9 & 10 & 11 & \mathrm{C} & \mathrm{P} & \mathrm{M}\end{array}$

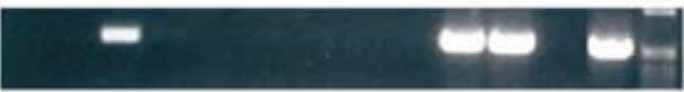

B
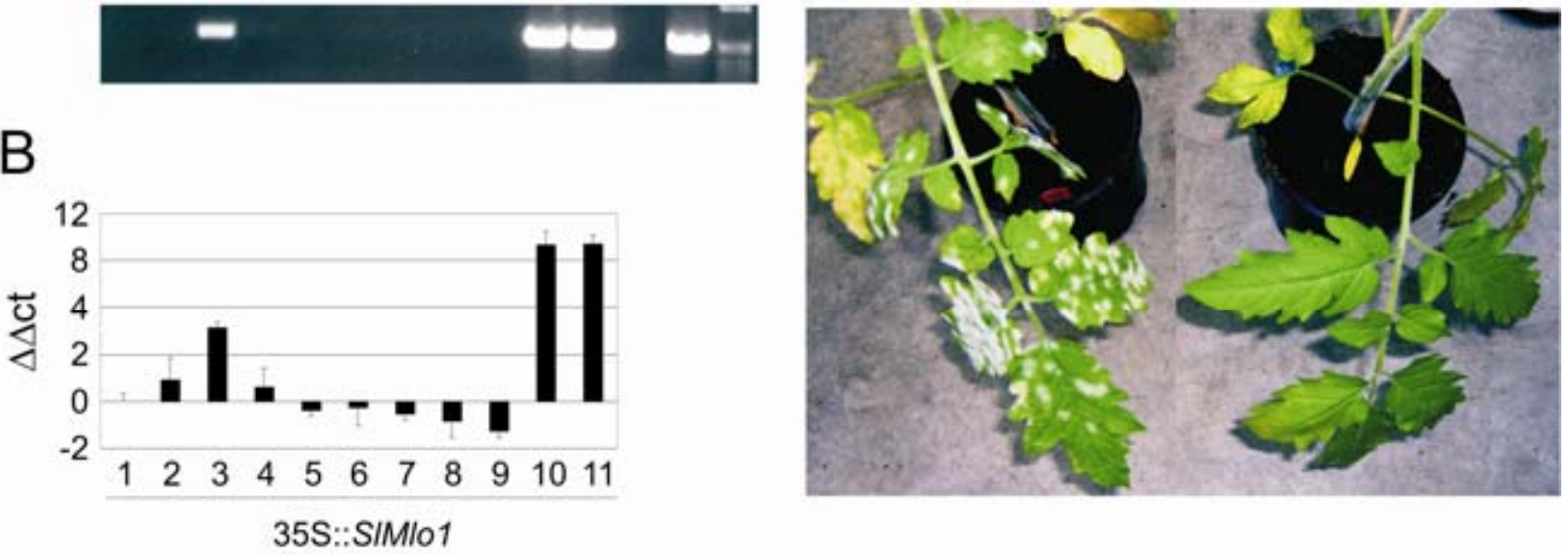

D

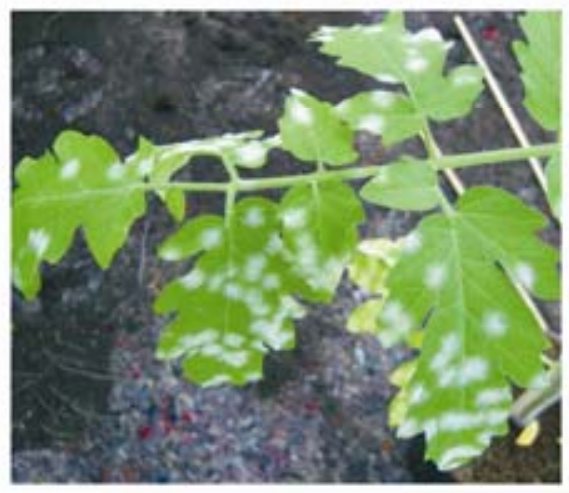

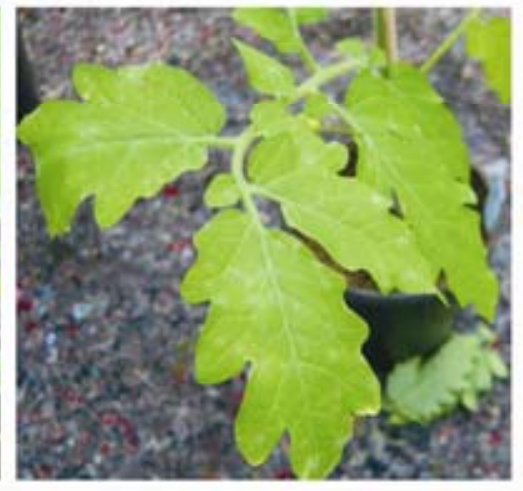

35S::SIMlo1

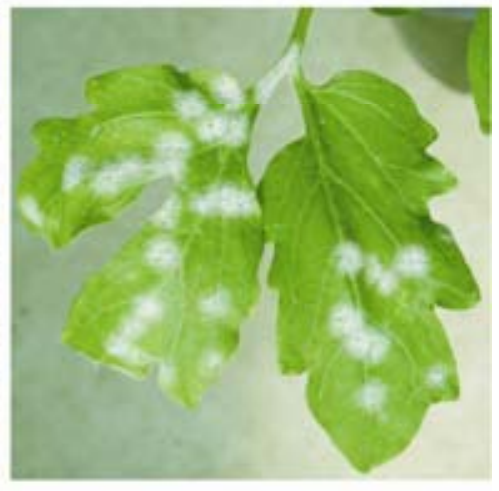

CV. MM

Fig. 6. Complementation of ol-2-mediated resistance in transgenic tomato lines overexpressing SlMlo1. A, Semiquantitative reverse transcription-polymerase chain reaction (RT-PCR) analysis ( 25 cycles) of eleven ( 1 to 11 ) transgenic $\mathrm{T}_{1}$ lines expressing $35 \mathrm{~S}$ ::SlMlo1 derived from the powdery mildew resistant line R26. RT-PCR reactions were performed using the SlMlo1 transgene-specific oligonucleotide combination SIMlo2/35S term. Note that the panel has been composed of various sections of a larger photograph of the respective agarose gel. $\mathrm{C}=$ water instead of template negative control, $\mathrm{P}=$ plasmid positive control, and $\mathrm{M}=$ size marker. B, Quantitative real-time PCR analysis of 35S::SIMlo1 transgene expression. Real-time PCR reactions were performed with the SlMlo1 transgene-specific oligonucleotide combination SIMlo2/35Sterm (SlMlo1 expression) and the actin-specific primer combination actin1/actin4 (actin expression). Relative expression levels based on the $\Delta \Delta$ ct values (average \pm standard deviation of four replicates) are indicated for the 11 transgenic lines in relation to line 1. Note that $\Delta \Delta \mathrm{ct}$ values are logarithmic indicators of differences in transcript accumulation. A second experiment yielded similar results. $\mathbf{C}$, Exemplary infection phenotypes upon powdery mildew (Oidium neolycopersici) challenge of $\mathrm{T}_{2}$ progeny of a transgenic line. Depicted are two descendants of $\mathrm{T}_{1}$ line 11 (described above), one being susceptible (left, $\mathrm{DI}=3$ ) and one being largely resistant (right, $\mathrm{DI}=0$ ). The photograph was taken 17 days postinoculation. D, Close-up views of powdery mildew-infected leaves of susceptible (left panel) and resistant (middle panel) progeny of a susceptible transgenic line ( $\mathrm{T}_{2}$ descendants of $\mathrm{T}_{1}$ line 11 expressing $35 \mathrm{~S}::$ SlMlo1) and the susceptible tomato wild-type control (cv. Moneymaker [MM]; right panel). Photographs were taken 17 days postinoculation. Note that infection phenotypes of the susceptible transgenic line and cv. MM are comparable $(\mathrm{DI}=3)$. 
In tomato, currently available EST indicate the presence of at least two paralogs that likely represent co-orthologs of AtMLO2, AtMLO6, and AtMLO12 in Arabidopsis (Figs. 2 and 3; Panstruga 2005b). Interestingly, unlike in Arabidopsis, lossof-function of a single gene (SlMlol) in tomato suffices to convey virtually full powdery mildew resistance (Bai et al., 2005). In Arabidopsis, AtMLO2, AtMLO6, and AtMLO12 exhibit unequal genetic redundancy (Briggs et al. 2006), and a mutation in the gene with the major 'susceptibility conferring' activity, AtMLO2, results merely in partial powdery mildew resistance (Consonni et al. 2006). This indicates that the functional specialization of Mlo isoforms evolved differently in Arabidopsis and tomato. In barley, like in tomato, a mutation in a single Mlo gene is sufficient to confer full powdery mildew resistance. However, unlike in tomato, Mlo is the only expressed gene copy of this (co-)ortholog cluster in barley. A closely sequence-related paralog, HvMlo2 (GenBank accession number Z95496) appears to represent a nonexpressed pseudogene ( $R$. Panstruga, unpublished findings). In sum, it seems that the genetic complexity and functional specialization within the Mlo co-ortholog cluster related to powdery mildew susceptibility significantly differs between various monocot and dicot plant species. With respect to plant breeding aspects, this implies that the time and effort required for obtaining powdery mildewresistant mlo mutants by either forward or reverse genetics or transgenic gene silencing approaches may also vary considerably between plant species.

Since in addition to cherry tomato, the $o l-2$ allele confers resistance in cultivated round tomatoes (S. lycopersicum, e.g., cvs. MM or SM), ol-2 might be useful for breeding in different types of tomatoes. Given the unusual durability of mlo-mediated powdery mildew resistance in barley (Lyngkjaer et al. 2000), the $o l-2$ allele promises to represent indeed a precious resource for future tomato breeding, the 19-bp deletion being a valuable polymorphism for marker-assisted breeding. Interestingly, resistant tomato lines lack any obvious pleiotropic phenotypes, such as early senescence-like leaf chlorosis of unchallenged plants, which has been reported to occur in both barley and Arabidopsis mlo mutants (data not shown; Consonni et al. 2006; Piffanelli et al. 2002). However, the extent of expression of pleiotropic effects in barley and Arabidopsis is considerably dependent on environmental conditions (Consonni et al. 2006; Jørgensen et al. 1992), leaving the possibility that lack of obvious pleiotropic phenotypes in ol-2 lines is based on the particular growth settings used in this study.

We observed moderately lower SlMlol transcript levels in $o l-2$ as compared to $\mathrm{Ol}-2$ genotypes, both in unchallenged as well as in powdery mildew-inoculated plants (Fig. 5A and B). Given that $o l-2$ likely is a null allele, one may hypothesize that the SIMlo1 protein exerts direct or indirect positive feedback regulation on the transcription of its own gene. Evidence for such a positive regulatory feedback loop has, however, neither been found in barley nor Arabidopsis mlo mutants (Piffanelli et al. 2002; C. Consonni and R. Panstruga, unpublished data). Unless this was a tomato-specific phenomenon, it is thus more likely that the observed difference in SIMlol transcript levels is due to intrinsic genetic variation of tomato (sub)species, e.g., within the SlMlol promoter region. Alternatively, the reduced transcript levels might result from one or more secondsite mutational events in SlMlol regulatory sequences following the inactivation of SlMlol function by the 19-bp deletion in the coding region. The current unavailability of SlMlol genomic sequences covering the $5^{\prime}$ regulatory region prevents testing these hypotheses at present. Intriguingly, despite lower SlMlol transcript levels, the ol-2 genotype retained rapid pathogen-responsiveness of SlMlo1 transcript accumulation following powdery mildew challenge (Fig. 5B).

The ol-2 allele is the second example, in addition to barley $m l o-11$, of a naturally occurring powdery mildew-resistant $m l o$ mutant and one of few examples, besides the Fer gene controlling iron uptake (Ling et al. 2002) and the Cnr fruit-ripening locus (Manning et al. 2006), of a cloned natural tomato mutant gene. Identification of a second natural Mlo loss-of-function allele indicates that this type of mutant might be more prevalent in nature than previously anticipated. In pea, recessively inherited broad-spectrum er-1 powdery mildew resistance is

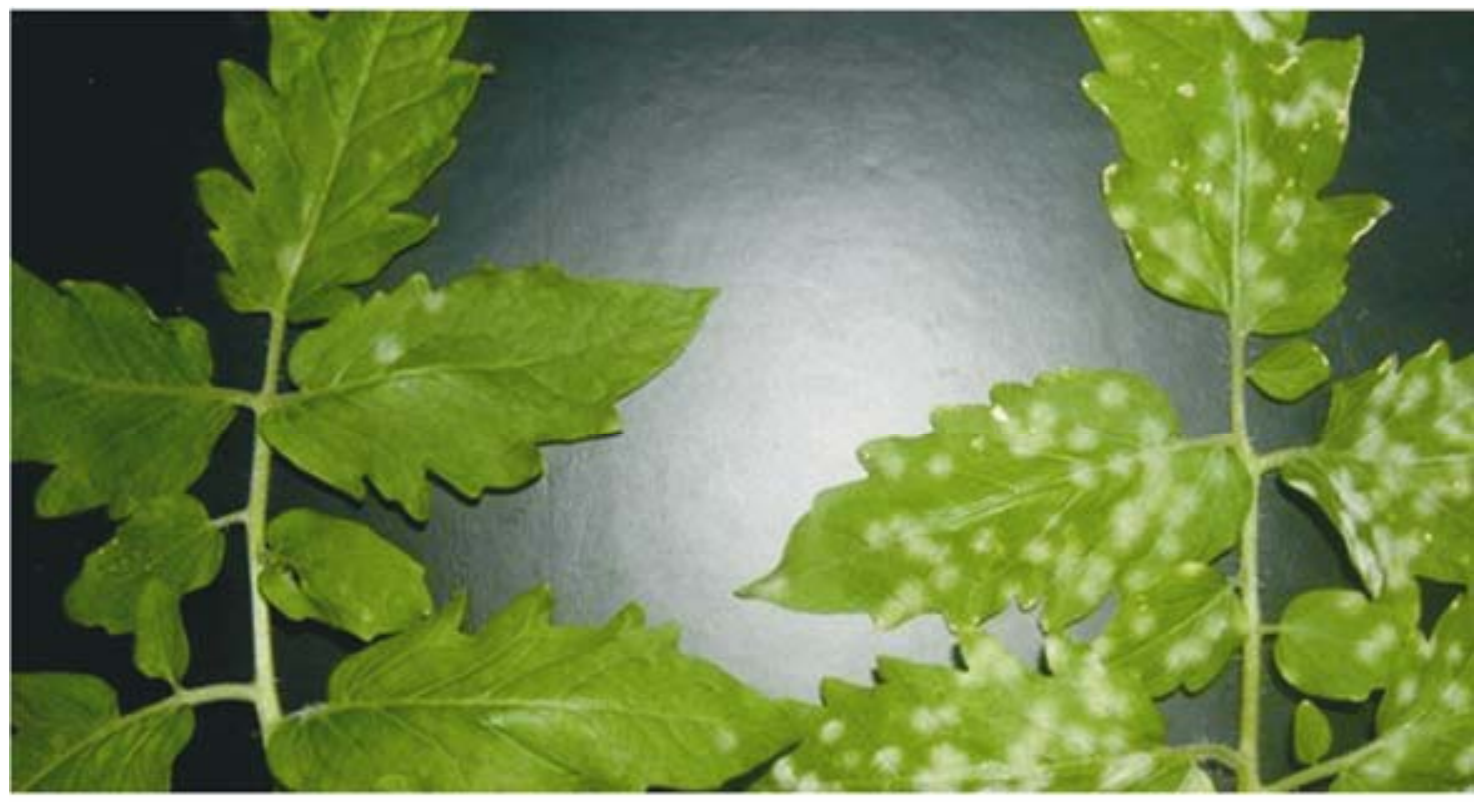

TRV::SIMlo1

TRV (empty vector)

Fig. 7. Virus-induced gene silencing of SlMlol confers enhanced powdery mildew resistance in wild-type tomato. Leaves of wild-type tomato (cv. Moneymaker) were infiltrated with agrobacteria harboring either a T-DNA with Tobacco rattle virus (TRV) carrying no insert (right) or a T-DNA with a TRV derivative harboring an SlMlol fragment (left). At 17 days after bacterial inoculation, leaves were challenged with Oidium neolycopersici. The photograph was taken 13 days after fungal inoculation. 
another candidate for natural mlo-based immunity (Fondevilla et al. 2006). Likewise, collections of novel barley accessions from various regions of the Old World represent further aspirants for natural mlo mutants (Czembor and Czembor 2002). It remains, however, to be seen whether $m l o-11$ and ol-2 signify the tip of the natural mlo mutant iceberg or whether they represent the rare exceptions.

The mlo-11 allele, originating from a barley landrace collected in Ethiopia, is characterized by the presence of a complex tandem-repeat array (Piffanelli et al. 2004). Resistance in mlo-11 is principally reversible due to a meiotic instability of the respective polymorphism. Based on this reversibility, it has been speculated that the barley mlo- 11 allele might represent an adaptive balanced polymorphism that could dampen the adverse effects of mlo mutants and thus be advantageous in natural barley populations facing varying pathogen pressure (Piffanelli et al. 2004). Unlike barley mlo-11, the mutational event in ol-2 tomato is rather simple, considered to be essentially meiotically stable and is supposed to represent the result of a fortuitous incident during meiotic replication or recombination. The likely presence of this mutational event in a heterozygous state in the original S. lycopersicum var. cerasiforme accession LA1230 (Ciccarese et al. 1998) may indicate that ol-2 is also maintained as a beneficial balanced polymorphism in natural tomato populations. Interestingly, the natural epigenetic mutation found at the $\mathrm{Cnr}$ fruit-ripening locus in the tomato hybrid cv. Liberto has also been reported to be subject to rare somatic reversion events and is also reversible (Manning et al. 2006).

The SlMlo1 null mutant allele present in ol-2 genotypes is presumably free of any evolutionary constraints. This circumstance would allow for the accumulation of further nucleotide alterations in the defective SlMlol gene over time. Absence of any additional sequence variation-besides the 19-bp deletionin the SlMlol coding region thus points to a recent origin of the ol-2 allele. The domestication history of tomato has not yet been fully resolved and is still controversially discussed (Nesbitt and Tanksley 2002; Peralta et al. in press). It was, however, recently proposed that $S$. lycopersicum var. cerasiforme represents an admixture of wild and cultivated tomatoes (Nesbitt and Tanksley 2002). Since ol-2 was originally identified in a Central American accession of $S$. lycopersicum var. cerasiforme, it seems that, reminiscent of barley mlo-11 (Piffanelli et al. 2004), the mutation in $o l-2$ originates from a domestication intermediate of a presently cultivated plant species. In addition, as in the case of mlo-11, the ol-2 mutational event possibly occurred after or coincident with the domestication of wild tomatoes. In the case of barley $m l o-11$, it has been speculated that the emergence of the natural allele might have compensated for the erosion of the natural genetic variation (including race-specific disease resistance) following barley domestication (Piffanelli et al. 2004). Occurrence of a second natural mlo allele derived from a domestication intermediate and of supposedly recent origin principally supports this hypothesis. Alternatively, owing to the known adverse affects of mutations in mlo genes, such as spontaneous callose deposition and early leaf senescence (Consonni et al. 2006; Piffanelli et al. 2002), mlo mutants might have a long-term selective disadvantage in natural settings, resulting in a selective sweep that prevents the discovery of evolutionary older mlo mutants that harbor additional DNA footprints. It appears that only the discovery and molecular analysis of more ancient $m l o$ mutants will allow discrimination between these two possibilities.

\section{MATERIALS AND METHODS}

\section{Plant and fungal material.}

Powdery mildew-susceptible $S$. lycopersicum cvs. MM and SM were used as wild-type tomato lines in this study. Homozy- gous resistant $\mathrm{F}_{3}$ lines R26 and R28, of a cross of the susceptible parent SM and the resistant parental line LC-95 (derived from S. lycopersicum var. cerasiforme LA-1230), served as representatives of the ol-2 resistance locus (De Giovanni et al. 2004). An $F_{2}$ population of a cross between MM and R28 was used to verify the cosegregation of the ol-2 allele with resistance. Arabidopsis Atmlo2, Atmlo6, and Atmlo12 single mutants as well as the respective double and triple mutants have been described before (Consonni et al. 2006). Plants were grown at $21^{\circ} \mathrm{C}$ (day) and $19^{\circ} \mathrm{C}$ (night) with 60 to $70 \%$ relative humidity. The Wageningen isolate of $O$. neolycopersici was maintained on cv. MM as described by Bai and associates (2005).

\section{Infection assays with $O$. neolycopersici.}

Disease tests were performed by spraying plants with a suspension of $O$. neolycopersici conidiospores (Bai et al. 2005). The inoculum was prepared from freshly sporulating leaves of heavily infected cv. MM plants. Conidiospores were washed in tap water and were used immediately. Four-week-old tomato plants were inoculated with an inoculum of $2 \times 10^{4}$ spores per

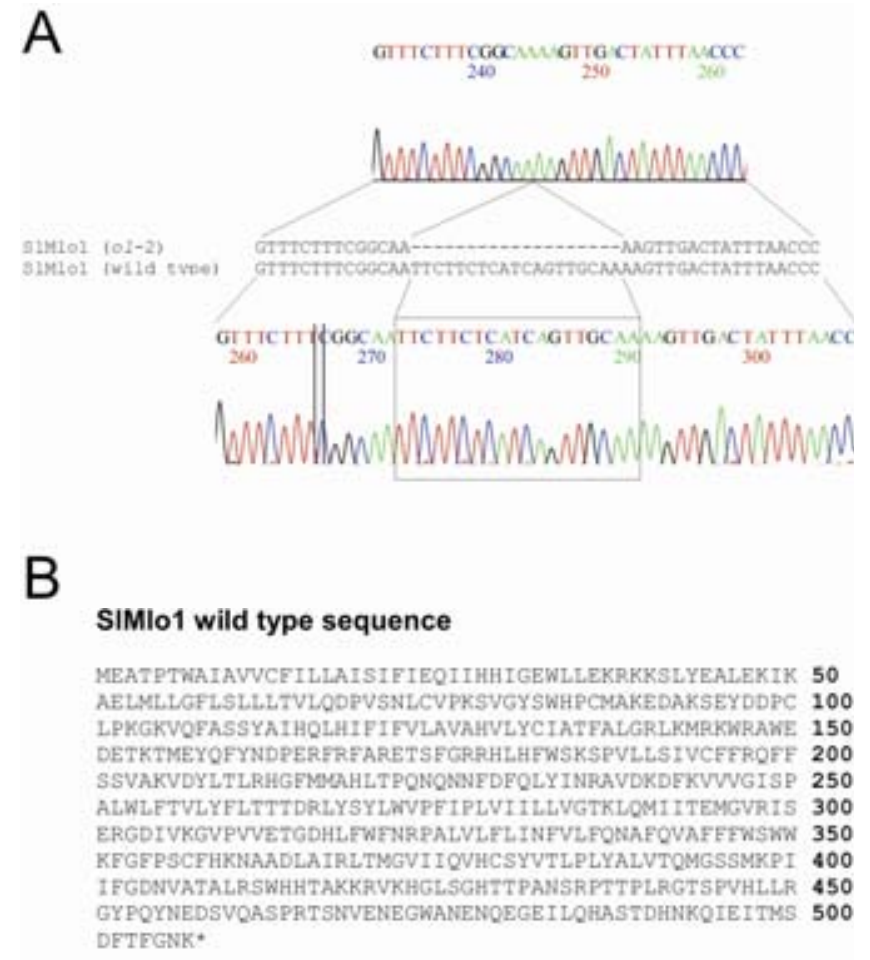

\begin{abstract}
SIMlo1 mutant variant (ol-2)
MEATPTWATAVVCETLLAISTFIEOIIHHIGEWLLEKRKKSLYEALEKTK $\mathbf{5 0}$ AELMLLOFLSLLLTVIODPVSNLCVPKSVGYSWHPCMAKEDAKSEYDDPC 100

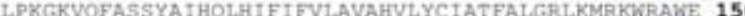
DETKTMEYOFYNDPEREFFARETSEGRAHLHFWSKSPVLLSTVCFEROKL 200 II*
\end{abstract}

Fig. 8. The ol-2 allele represents a SIMlol mutant variant with a 19-bp deletion in the coding region. A, Segment of sequence trace files obtained by direct sequencing of a full-size SlMlol reverse transcription-polymerase chain reaction product using either RNA from leaves of resistant line R26 or RNA from wild-type tomato (cv. Super Marmande) as source material. Corresponding sequence alignments of SIMlol wild-type cDNA and the mutant variant emphasize the 19-bp deletion in the SlMlol coding region of ol-2 plants (boxed in the SlMlol wild-type sequence). B, Consequence of the 19bp deletion on the conceptual SIMlo1 amino-acid sequence. Upper panel, predicted wild-type SIMlo1 amino-acid sequence; lower panel, predicted mutant SIMlo1 amino-acid sequence. The last four amino acids of the mutant protein variant (highlighted in yellow) are due to the frameshift and are not present in the SIMlo1 wild-type polypeptide. 
milliliter, while five-week-old Arabidopsis plants were sprayed with an inoculum of $1 \times 10^{5}$ spores per milliliter. A DI scale of $0,1,2$, and 3 was used to semiquantitatively assess infection phenotypes: $0=$ no visible fungal sporulation, $1=$ few fungal colonies, $2=$ up to $30 \%$ of the leaf area covered with fungal colonies, and $3=$ more than $30 \%$ of the leaf area covered with fungal colonies.

\section{Phylogenetic analysis.}

For phylogenetic analysis of Mlo proteins, the Phylip 3.66 software package was used (Felsenstein 1989). First, a multiple sequence alignment (generated by CLUSTALW) was established and manually optimized (Supplementary Fig. 1). A distance matrix was calculated by PROTDIST from the multiple sequence alignment and was then transformed into a tree using the neighbor-joining method (NEIGHBOR). The resulting phylogenetic tree was visualized by TREEVIEW. For bootstrap support, SEQBOOT (1,000 replicates), PROTDIST, NEIGHBOR, and CONSENSE algorithms were sequentially applied. All programs were run with standard parameters.

\section{SlMlo mapping.}

A core set of 50 tomato IL covering overlapping segments of all 12 tomato chromosomes (Eshed and Zamir 1995) was used for mapping the SlMlo genes. Full-size SlMlol and partial SlMlo2 cDNAs were radioactively labeled and hybridized to filters harboring genomic DNAs of both parental lines digested with a variety of restriction enzymes to detect polymorphisms between the two parental lines. Subsequently, filters representing genomic DNAs of the IL cut with the selected restriction enzyme were used for the actual mapping process.

\section{Transgenic tomato lines.}

Tomato EST clones cLEC80N18 (GenBank accession BI923467) and cTOC20K10 (GenBank accession BI931548) representing either incomplete or disordered SlMlo1 cDNAs were recombined to obtain a bona fide full-length SlMlo1 cDNA clone. The respective cDNA was shuttled via plasmid pRT101 (harboring Cauliflower mosaic virus 35S promoter and terminator sequences; Töpfer et al. 1987) into binary vector pPZP211 (GenBank accession number U10490; Hajdukiewicz et al. 1994), using appropriate restriction sites. Agrobacterium-mediated transformation of resistant line R26 and subsequent selection of transgenic lines was performed as described (Knapp et al. 1994).

\section{VIGS.}

The TRV vectors, derived from the bipartite TRV virus, were previously described (Liu et al. 2002). The VIGS SIMlol construct was engineered by cloning a 293-bp genomic DNA fragment from the central part of the SlMlol coding region into pTRV2. This DNA fragment, corresponding to a central part of the SlMlol cDNA (bp 806 to 973; Fig. 2) harboring an intron of $94 \mathrm{bp}$, was amplified with primers 5'-gtgacggatcc CGTATCTTTGGGTGCCATTT-3' and 5'-gtgacggtaccCAGGG CGATTAAACCAGAAA-3' (lowercase letters indicate the overhang harboring the restriction sites of Asp 718 and BamHI) from genomic tomato DNA. The PCR product was digested with Asp718 and BamHI and was ligated into pTRV2.

For Agrobacterium tumefaciens-mediated virus infection, cultures of $A$. tumefaciens GV3101 containing pTRV1, empty vector control, and each of the constructs derived from pTRV2 were grown and harvested as described (van der Hoorn et al. 2000). Equal volumes of cultures harboring pTRV1 and pTRV2 were mixed and were subsequently infiltrated into the lower (adaxial) side of cotyledons of 10-day-old tomato seedlings, using a 1-ml syringe lacking a needle. Two weeks after infiltration, plants were inoculated with $O$. neolycopersici.
RNA isolation and semiquantitative RT-PCR.

To monitor SlMlol transcript accumulation, total RNAs were extracted using the Trizol reagent (Invitrogen Life Technologies Co., Carlsbad, CA, U.S.A.) and were purified with a NucleoSpin RNA II kit (Macherey-Nagel GmbH \& Co. KG, Düren, Germany). cDNAs were synthesized with oligo(dT) $)_{18}$ primers using the SuperScript III RTS first-strand cDNA synthesis kit (Invitrogen).

For RT-PCR with MM and R28 (Fig. 5A), actin cDNA was amplified with primers 5'-GCTCCACCAGAGAGGAAATAC AGT-3' and 5'-CATACTCTGCCTTTGCAATCCA-3'. The expression of SIMLO1 was monitored by marker cTOC20 by amplifying a transcript with primers 5'-TGTGGTTTGCTTCA TCTTGC-3' and 5'-ACCAACACTCTTGGGGACAC-3'. For RT-PCR with $\mathrm{F}_{2}$ plants (Fig. $5 \mathrm{~B}$ ), actin cDNA was amplified with primers published by Ditt and associates (2001). The expression of SlMlol was monitored by amplifying sequences flanking the 19-bp deletion in the SIMLO1 cDNA with primers 5'-ATGGGAGGATGAAACAAAAAC-3' and 5'-ACAATCGA TCGGTAGTAGTCAGA-3'.

For analysis of SlMlol expression in $\mathrm{T}_{1}$ transgenic lines (Fig. 6A and B), oligonucleotides actin1 (5'-TGAGCCTCATT TTAAGCTC-3') and actin4 (5'-GAAATACAACTCTTCTACA TA-3') were used for the amplification of the $1.3-\mathrm{kb}$ actin amplicon serving as internal reference. Transgenic SlMlol was selectively amplified by oligos SIMlo2 (5'-TTCCCATCTTGCTTTCATAAG-3', binding at the $3^{\prime}$ end of SIMlo1, forward primer) and 35Sterm (5'-CTACTCACACATTATTCTGG-3', binding in the Cauliflower mosaic virus $35 \mathrm{~S}$ transcriptional terminator sequence present in the binary vector, reverse primer), yielding a 0.55-kb PCR fragment. Real-time PCR was performed using SYBR green chemistry (Brilliant SYBR Green QPCR core reagent kit; Stratagene, La Jolla, CA, U.S.A.) on a iQ5 Multicolor real-time PCR detection system (Bio-Red, Munched, Germany). Relative transcript levels were calculated on the basis of the $\Delta \Delta$ ct method.

\section{Cosegregation of the 19-bp deletion in SlMlo1 with powdery mildew resistance.}

Total DNA was extracted from leaves of $F_{2}$ plants using the cetyltrimethylammonium bromide DNA isolation method (Brugmans et al. 2003) and was used for genotyping the $F_{2}$ progeny with a codominant M/SIMlo1 marker. This PCR marker, spanning the mutant site in $o l-2$, was amplified with oligonucleotides 5'-ACCCTTAAGAAACTAGGGCAAA-3' (forward primer) and 5'-ACCATCATGAACCCATGTCT-3' (reverse primer) with an annealing temperature of $55^{\circ} \mathrm{C}$. Product size is 197 bp for wild-type SlMlol (Ol-2 genotype) and $178 \mathrm{bp}$ for the homozygous ol-2 mutant genotype, while heterozygous individuals exhibit the presence of both amplicons.

\section{ACKNOWLEDGMENTS}

We thank A. Kalde, U. Pfordt, U. Tartler, J. Vossen, and A. Loonen for excellent technical assistance. S. Dinesh-Kumar (Yale University, New Haven, CT, U.S.A.) kindly provided pTRV1, pTRV2, and pTRV2::PDS (phytoene desaturase). Work in the lab of R. Panstruga is funded by grants of the Max-Planck Society, including a Ph.D. fellowship of the International Max Planck Research School to N. Zappel, and the Deutsche Forschungsgemeinschaft. Work in the lab of Y. Bai is supported by an internal grant from Wageningen UR Plant Breeding.

\section{LITERATURE CITED}

Bai, Y., van der Hulst, R., Bonnema, G., Marcel, T. C., Meijer-Dekens, F., Niks, R. E., and Lindhout, P. 2005. Tomato defense to Oidium neolycopersici: Dominant $\mathrm{Ol}$ genes confer isolate-dependent resistance via a different mechanism than recessive $o l-2$. Mol. Plant-Microbe Interact. 18:354-362. 
Bonnema, G., Berg, P., and Lindhout, P. 2002. AFLPs mark different genomic regions compared with RFLPs: A case study in tomato. Genome 45:217-221.

Briggs, G. C., Osmont, K. S., Shindo, C., Sibout, R., and Hardtke, C. S 2006. Unequal genetic redundancies in Arabidopsis-A neglected phenomenon? Trends Plant Sci. 11:492-498.

Brugmans, B., Van der Hulst, R. G. M., Visser, R. G. F., Lindhout, P. and Van Eck, H. J. 2003. A new and versatile method for the successful conversion of AFLP (TM) markers into simple single locus markers. Nucleic Acids Res. 31:9-17.

Büschges, R., Hollricher, K., Panstruga, R., Simons, G., Wolter, M., Frijters, A., van Daelen, R., van der Lee, T., Diergaarde, P., Groenendijk, J., Töpsch, S., Vos, P., Salamini, F., and Schulze-Lefert, P. 1997. The barley Mlo gene: A novel control element of plant pathogen resistance. Cell 88:695-705

Ciccarese, F., Amenduni, M., Schiavone, D., and Cirulli, M. 1998. Occurrence and inheritance of resistance to powdery mildew (Oidium lycopersici) in Lycopersicon species. Plant Pathol. 47:417-419.

Consonni, C., Humphry, M. E., Hartmann, H. A., Livaja, M., Durner, J., Westphal, L., Vogel, J., Lipka, V., Kemmerling, B., Schulze-Lefert, P., Somerville, S. C., and Panstruga, R. 2006. Conserved requirement for a plant host cell protein in powdery mildew pathogenesis. Nature Genet. 38:716-720.

Czembor, J. H., and Czembor, H. J. 2002. Selections from barley landrace collected in Libya as new sources of effective resistance to powdery mildew (Blumeria graminis f. sp hordei). Rostl. Vyroba 48:217-223.

De Giovanni, C., Dell'Orco, P., Bruno, A., Ciccarese, F., Lotti, C., and Ricciardi, L. 2004. Identification of PCR-based markers (RAPD, AFLP) linked to a novel powdery mildew resistance gene (ol-2) in tomato. Plant Sci. 166:41-48.

Devoto, A., Piffanelli, P., Nilsson, I., Wallin, E., Panstruga, R., von Heijne, G., and Schulze-Lefert, P. 1999. Topology, subcellular localization, and sequence diversity of the Mlo family in plants. J. Biol. Chem. 274:34993-35004.

Devoto, A., Hartmann, H. A., Piffanelli, P., Elliott, C., Simmons, C., Taramino, G., Goh, C. S., Cohen, F. E., Emerson, B. C., Schulze-Lefert, P., and Panstruga, R. 2003. Molecular phylogeny and evolution of the plant-specific seven-transmembrane MLO family. J. Mol. Evol. 56:7788.

Ditt, R. F., Nester, E. W., and Comai, L. 2001. Plant gene expression response to Agrobacterium tumefaciens. Proc. Natl. Acad. Sci. U.S.A. 98:10954-10959.

Elliott, C., Müller, J., Miklis, M., Bhat, R. A., Schulze-Lefert, P., and Panstruga, R. 2005. Conserved extracellular cysteine residues and cytoplasmic loop-loop interplay are required for functionality of the heptahelical MLO protein. Biochem. J. 385:243-254.

Eshed, Y., and Zamir, D. 1995. An introgression line population of $\mathrm{Ly}$ copersicon pennellii in the cultivated tomato enables the Identification and fine mapping of yield-associated QTL. Genetics 141:1147-1162.

Felsenstein, J. 1989. PHYLIP-Phylogeny Inference Package (Version 3.2). Cladistics 5:164-166.

Fondevilla, S., Carver, T. L. W., Moreno, M. T., and Rubiales, D. 2006 Macroscopic and histological characterisation of genes er1 and er2 for powdery mildew resistance in pea. Eur. J. Plant Pathol. 115:309-321.

Freisleben, R., and Lein, A. 1942. Über die Auffindung einer mehltauresistenten Mutante nach Röntgenbestrahlung einer anfälligen reinen Linie von Sommergerste. Naturwissenschaften 30:608.

Hajdukiewicz, P., Svab, Z., and Maliga, P. 1994. The small, versatile pPZP family of Agrobacterium binary vectors for plant transformation. Plant Mol. Biol. 25:989-994.

Jones, H., Whipps, J. M., and Gurr, S. J. 2001. The tomato powdery mildew fungus Oidium neolycopersici. Mol. Plant Pathol. 2:303-309.

Jørgensen, J. H. 1992. Discovery, characterization and exploitation of Mlo powdery mildew resistance in barley. Euphytica:63:141-152.

Kiss, L., Cook, R. T. A., Saenz, G. S., Cunnington, J. H., Takamatsu, S., Pascoe, I., Bardin, M., Nicot, P. C., Sato, Y., and Rossman, Y. 2001. Identification of two powdery mildew fungi, Oidium neolycopersici $\mathrm{sp}$. nov. and $O$. lycopersici, infecting tomato in different parts of the world. Mycol. Res. 105:684-697.

Knapp, S., Larondelle, Y., Rossberg, M., Furtek, D., and Theres, K. 1994.
Transgenic tomato lines containing $D s$ elements at defined genomic positions as tools for targeted transposon tagging. Mol. Gen. Genet. 243:666-673.

Ling, H.-Q., Bauer, P., Bereczky, Z, Keller, B., and Ganal, M. 2002. The tomato fer gene encoding a bHLH protein controls iron-uptake responses in roots. Proc. Natl. Acad. Sci. U.S.A. 99:13938-13943.

Liu, Y. L., Schiff, M., and Dinesh-Kumar, S. P. 2002. Virus-induced gene silencing in tomato. Plant J. 31:777-786.

Lyngkjaer, M. F., Newton, A. C., Atzema, J. L., and Baker, S. J. 2000. The barley mlo-gene: An important powdery mildew resistance source. Agronomie 20:745-756.

Manning, K., Tor, M., Poole, M., Hong, Y., Thompson, A. J., King, G. J., Giovannoni, J. J., and Seymour, G. B. 2006. A naturally occurring epigenetic mutation in a gene encoding an SBP-box transcription factor inhibits tomato fruit ripening. Nature Genet. 38:948-952.

Nesbitt, T. C., and Tanksley, S. D. 2002. Comparative sequencing in the genus Lycopersicon: Implications for the evolution of fruit size in the domestication of cultivated tomatoes. Genetics 162:365-379.

Panstruga R. 2005a. Serpentine plant MLO proteins as entry portals for powdery mildew fungi. Biochem. Soc. Trans. 33:389-392.

Panstruga, R. 2005b. Discovery of novel conserved peptide domains by ortholog comparison within plant multi-protein families. Plant Mol. Biol. 59:485-500.

Panstruga, R., Molina-Cano, J. L., Reinstädler, A., and Müller, J. 2005. Molecular characterization of mlo mutants in North American two- and six-rowed malting barley cultivars. Mol. Plant Pathol. 6:315-320.

Pavan, S., Zheng, Z., van den Berg, P., Lotti, C., De Giovanni, C., Borisova, M., Lindhout, P., de Jong, H., Ricciardi, L., Visser, R., and Bai, Y. Mapvs. homology-based cloning for the recessive gene ol-2 conferring resistance to tomato powdery mildew. Euphytica. In press.

Peralta, I. E., Knapp, S., and Spooner, D. M. Taxonomy of tomatoes: A revision of wild tomatoes (Solanum section Lycopersicon) and their outgroup relatives in sections Juglandifolia and Lycopersicoides. Systematic Botany Monographs Vol. 84. American Society of Plant Taxonomists. Ann Arbor, MI, U.S.A. In press.

Piffanelli, P., Zhou, F. S., Casais, C., Orme, J., Jarosch, B., Schaffrath, U., Collins, N. C., Panstruga, R., and Schulze-Lefert, P. 2002. The barley MLO modulator of defense and cell death is responsive to biotic and abiotic stress stimuli. Plant Physiol. 129:1076-1085.

Piffanelli, P., Ramsay, L., Waugh, R., Benabdelmouna, A., D'Hont, A., Hollricher, K., Jørgensen, J. H., Schulze-Lefert, P., and Panstruga, R. 2004. A barley cultivation-associated polymorphism conveys resistance to powdery mildew. Nature 430:887-891.

Takamatsu, S. 2004. Phylogeny and evolution of the powdery mildew fungi (Erysiphales, Ascomycota) inferred from nuclear ribosomal DNA sequences. Mycoscience 45:147-157.

Töpfer, R., Matzeit, V., Gronenborn, B., Schell, J., and Steinbiss, H. H 1987. A set of plant expression vectors for transcriptional and translational fusions. Nucleic Acids Res. 15:5890-5896.

Van der Hoorn, R. A. L., Laurent, F., Roth, R., and De Wit, P. J. G. M. 2000. Agroinfiltration is a versatile tool that facilitates comparative analyses of $A v r 9 / C f$-9-induced and $A v r 4 / C f$-4-induced necrosis. Mol. Plant-Microbe Interact. 13:439-446.

Xiao, S. Y., Ellwood, S, Calis, O., Patrick, E., Li, T. X., Coleman, M., and Turner J. G. 2001. Broad-spectrum mildew resistance in Arabidopsis thaliana mediated by RPW8. Science 291:118-120.

\section{AUTHOR-RECOMMENDED INTERNET RESOURCES}

CLUSTALW multiple sequence alignment: www.ebi.ac.uk/clustalw/ NCBI Unigene database: www.ncbi.nlm.nih.gov/sites/entrez?db=unigene NCBI UniGene database, tomato Les.746: www.ncbi.nlm.nih.gov/UniGene/clust.cgi?ORG=Les\&CID=746

PHYLIP phylogenetic analysis: evolution.gs.washington.edu/phylip.html

University of Califormia Davis Tomato Genetics Resource Center (TGRC) tgrc.ucdavis.edu/Data/Acc/dataframe.aspx?start=GIS_dataoption.aspx\& navstart=nav.html

TREEVIEW phylogenetic tree visualization: taxonomy.zoology.gla.ac.uk/rod/treeview.html 